\title{
Immunoarchitecture of lymphoid tissue in HIV-infection during antiretroviral therapy correlates with viral persistence
}

\author{
Llúcia Alòs ${ }^{1}$, Pilar Navarrete ${ }^{1}$, Vanesa Morente ${ }^{1}$, Felipe Garcia ${ }^{2}$, Marta Garrido ${ }^{1}$, \\ Montse Plana ${ }^{3}$, Anna Mozos ${ }^{1}$, Anna López ${ }^{3}$, Cristina Gil ${ }^{4}$, Tomás Pumarola ${ }^{4}$, \\ Miguel Caballero ${ }^{5}$, Jose L Blanch ${ }^{5}$, Emilio Fumero ${ }^{2}$, José M Miró ${ }^{2}$, Teresa Gallart ${ }^{3}$, \\ José M Gatell ${ }^{2}$ and Elias Campo ${ }^{1}$
}

${ }^{1}$ Departments of Pathology; ${ }^{2}$ Department of Infectious Diseases; ${ }^{3}$ Department of Immunology; ${ }^{4}$ Department of Microbiology and ${ }^{5}$ Department of Otolaryngology of Hospital Clinic of Barcelona, Institut d'Investigacions Biomèdiques August Pi i Sunyer (IDIBAPS), University of Barcelona, Spain

\begin{abstract}
Plasma viral load and T-cell subset determinations in blood are the markers used for monitoring HIV-1 infection. However, key pathogenesis events, viral replication and most immunologic changes occur in the lymphoid tissues. We have studied the tonsillar biopsies of 30 patients in the early stages of the disease, before initiating treatment and after 12 and $\mathbf{3 6}$ months of fully effective highly active antiretroviral therapy. We have investigated the HIV RNA by polymerase chain reaction (lymphoid tissue viral load), the immunohistochemical HIV-p24 antigen expression, as well as the lymphoid tissue architecture and lymphoid cell subsets using morphometry. The lymphoid tissue viral load and the immunoexpression of p24, which was found to be mainly associated with follicular dendritic cells, decreased significantly after treatment, but did not disappear in all cases, even after 36 months of treatment. A significant improvement of the lymphoid tissue architecture was also observed after treatment, with recovery of follicular structures. These histological changes correlated with the lymphoid tissue viral load. Moreover, the counts of CD4 + increased whereas CD8 + and cytotoxic lymphocytes (CD8 + granzyme B+) decreased significantly, the latter in both interfollicular and intrafollicular areas. However, these cellular counts after treatment did not reach those of lymphoid tissue of non-HIV-infected patients used as control cases. Naive (CD45RA + ) and memory $(C D 45 R O+)$ cells also improved significantly after treatment. In conclusion, in HIV-infection the impact of treatment can only be assessed completely in the lymphoid tissue reservoir, where most of the virus is stored and associated with follicular dendritic cells. Highly active antiretroviral therapy produces a significant recovery of lymphoid tissue architecture and lymphoid cell subsets, which are associated with the decrease of lymphoid tissue viral load. However, these parameters studied in lymphoid tissue are not re-established completely, even after $\mathbf{3 6}$ months of highly active antiretroviral therapy.
\end{abstract}

Modern Pathology (2005) 18, 127-136, advance online publication, 24 September 2004; doi:10.1038/modpathol.3800267

Keywords: HAART; HIV; immunohistochemistry; lymphoid tissue; morphometry; p24

In HIV-1 infection, viral replication and storing take place in lymphoid tissues. The infection generates a large number of virions, most of which are stored in immune complexes associated with follicular dendritic cells. ${ }^{1-4}$ These cells play an important role in the transmission of HIV to cells and represent a

Correspondence: Dr L Alòs, MD, Department of Pathology, Hospital Clínic of Barcelona, Villarroel, 170, 08036 Barcelona, Spain.

E-mail: lalos@clinic.ub.es

Received 14 May 2004; revised and accepted 16 July 2004; published online 24 September 2004 major reservoir for HIV, facilitating the infection of $\mathrm{CD} 4+\mathrm{T}$ lymphocytes and producing a subsequent systemic spread. ${ }^{1}$ Consequently, there is an impairment of CD4 + helper or inducer cells, probably due to several mechanisms, such as a persistent immune activation with an increased T-cell proliferation and cell death, ${ }^{5-8}$ and a decrease of cell production by preventing maturity of lymphoid precursors. ${ }^{9,10}$ $\mathrm{CD} 4+\mathrm{T}$ lymphocytes are involved either directly or indirectly in most of the body's immunologic functions and their destruction results in progressive impairment of the immune response and ultimately in the marked immunodeficiency 
characteristic of AIDS. Moreover, the HIV-1 infection induces an increase of the specific anti-HIV cytotoxic reaction, for which cytotoxic CD8 + T cells are responsible. These cells are recruited to the germinal center of the lymphoid tissue by a chemotactic effect of the virus, but in most cases, this cytotoxic action is insufficient to stop the viral replication. As a consequence of these facts the follicular dendritic cells are destroyed as innocent bystanders, resulting in damage to their meshwork. ${ }^{11}$ These changes in the T-lymphoid cell subsets induced by the virus, led to a progressive alteration in the lymphoid tissue architecture, that correlates with the evolution of the disease. ${ }^{12,13}$

The introduction of highly active-antiretroviral therapy (HAART) has changed the prognosis of this disease, due to the decrease of the virus replication, and the $\mathrm{CD} 4+\mathrm{T}$ lymphocyte recovery. Under HAART, the CD4 $+\mathrm{T}$ cell increase is determined by a decrease of dying $\mathrm{T}$ cells,,${ }^{6,7,14}$ and also by thymic output. ${ }^{15,16}$ These events are associated with a suppression of the plasma viral load and an increase of $\mathrm{CD} 4+\mathrm{T}$ lymphocytes in peripheral blood. However, in spite of this improvement, after interrupting HAART there is a rebound of the plasma viral load again. This fact occurs even when the plasma viral load had been undetectable and it is attributed to the persistence of lymphoid tissue viral reservoir. ${ }^{17,18}$ Moreover, these patients present an incomplete immune restoration measured by means of phenotypical and functional parameters, even when T-cell counts have improved in peripheral blood. ${ }^{19}$ Previous studies of the lymphoid tissue in HIV-infected persons on HAART have demonstrated a partial improvement of the lymphoid tissue architecture after 12 months of treatment, ${ }^{20,21}$ but there are no studies comprising longer follow-up.

The overall goal of the present study was to determine the viral reservoir in lymphoid tissue and its relationship with the changes in the immunoarchitecture of lymphoid tissue, in patients successfully treated with HAART for a long period. To carry out this aim, we have studied the tonsillar lymphoid tissue of 30 HIV-1-infected patients, before initiating HAART and after 12 and 36 months of treatment. We have determined the HIV-1 RNA by PCR and the immunoexpression of p24 antigen. The lymphoid tissue architecture has been studied by morphometry and we have quantified the lymphoid cell subsets. Moreover, these parameters in lymphoid tissue have been correlated with the plasma viral load and T-cell subsets in peripheral blood, determined in parallel.

\section{Materials and methods}

\section{Patient Population}

In all, 30 adult patients with chronic asymptomatic HIV-1 infection and CD4 + lymphocyte count above 500 cells $\times 10^{6} / 1$, not previously treated with anti- retroviral therapy, were eligible for tonsillar biopsies. All patients gave written informed consent to be included in the present survey. The study was approved by the local ethics committee. The patients were treated with HAART, defined as a combination of at least two nucleoside reverse transcriptase inhibitors plus a protease and/or a non-nucleoside reverse transcriptase inhibitor.

Five tonsillar therapeutic resections of five nonHIV-infected persons, with sleep apnea syndrome were used as control cases.

\section{Lymphoid Tissue Collection and Selection of Cases}

The tonsillar biopsies were performed in all patients before initiating HAART and after 12 months of treatment. In six cases, tonsillar biopsies were obtained also after 36 months of treatment. Each sample of tonsillar tissue was split into two parts, one-half was frozen immediately in liquid nitrogen and used to determine the lymphoid tissue viral load; the other half was formalin-fixed and paraffinembedded for histological and immunohistochemical studies. From the latter routine, hematoxylineosin stain was carried out. Only biopsies with an adequate amount of lymphoid tissue were selected for immunohistochemical and morphometric analyses. We could evaluate 26 initial biopsies; 28 biopsies performed after 12 months of treatment; and the six biopsies after 36 months of treatment. However, all cases were included in this survey, as we consider they could give us useful information.

\section{Lymphoid Tissue Viral Load}

Lymphoid tissue viral load was determined in frozen tonsillar tissues using the NucliSens HIV-1 RNA QT Assay (Organon Teknika, Turnhout, Belgium). RNA was extracted using the Boom extraction method recommended by the manufacturer's (Organon Teknika) protocol. In brief, 80 slices of $10 \mu \mathrm{m}$ from each specimen (mean total weight $18 \mathrm{mg}$ ) were added to $1 \mathrm{ml}$ guanidine thiocyanate containing lysis buffer. After homogenization, $10 \mu \mathrm{l}$ of each sample was added to $1 \mathrm{ml}$ of new lysis buffer with RNA internal standards (NucliSens) and $50 \mu \mathrm{l}$ silica suspension to bind nucleic acid. After centrifugation, the silica pellet was washed five times (twice with guanadine thiocyanate-based wash buffer, twice with $70 \%$ ethanol and once with acetone). Subsequently, nucleic acid was eluted using $50 \mu$ l elution buffer (EDTA). The amplification reaction used $5 \mu$ l of this nucleic acid solution with $45 \mu \mathrm{l}$ specimen diluent and NASBA (NucliSens). The amount of RNA was expressed as copies per miligram of tissue. The limit of detection of this method for HIV-1 RNA was calculated to be in the order of 40 copies/mg lymphoid tissue. 


\section{Immunohistochemical Techniques}

Immunohistochemical studies were carried out using both the automated immunohistochemical system TechMate 500 (Dako, Carpinteria, CA, USA), and the EnVision system (Dako). Briefly, $4 \mu \mathrm{m}$ sections were deparaffinized and hydrated through graded alcohols and water. Peroxidase was blocked for $7.5 \mathrm{~min}$ in ChemMate peroxidase-blocking solution (Dako). Then the slides were incubated with the primary antibodies for $30 \mathrm{~min}$ and washed in ChemMate buffer solution (Dako). The peroxidase labelled polymer was then applied for $30 \mathrm{~min}$. After washing in ChemMate buffer solution, the slides were incubated with diaminobenzidine substrate chromogen solution and counterstained with hematoxylin. The antibodies used in the study, their sources and dilutions are shown in Table 1. Double immunohistochemical stains were performed in order to determine cytotoxic T lymphocytes (stains for CD8 and granzyme B) and proliferating naive lymphocytes (stains for CD45RA and Ki-67). For this purpose, bindings of granzyme $\mathrm{B}$ and Ki-67 antibodies were visualized using the EnVision system, as explained above. The sections were then heat treated again for $5 \mathrm{~min}$ and incubated with CD8 and CD45RA antibodies, respectively. The second antibodies were then detected with APAAP using New Fuchsin as red chromogen.

\section{Study of the Morphology of Lymphoid Tissue and the Immunoreaction for p24}

Tonsil tissue sections were examined blindly to evaluate the morphological characteristics of the lymphoid tissue and immunohistochemical results for p24 by two independent observers (LA and PN or VM), who were not aware either of the dates of tonsil biopsy nor the clinical situation of the patients. The morphological study of the lymphoid tissue was performed on hematoxylin-eosin sections, with the aid of immunohistochemical stain for CD20 and CD21 in order to detect secondary follicles. The histological characteristics of the lymphoid tissue

Table 1 Antibodies used in the study

\begin{tabular}{llll}
\hline Antibody & Source & Clone & Dilution \\
\hline P24 & Dako & Kal-1 & $1: 5$ \\
CD20 & Dako & L26 & $1: 80$ \\
CD21 & Dako & $1 \mathrm{~F} 8$ & $1: 100$ \\
CD4 & NCL & 1F6 & $1: 5$ \\
CD8 & NCL & 4 B11 & $1: 10$ \\
Granzyme B & Monosan & GrB-7 & $1: 50$ \\
CD45RO & CCT & A6 & $1: 200$ \\
CD45RA & Dako & 4 KB5 & $1: 25$ \\
Ki-67 & IMT & MIB-1 & $1: 400$ \\
& & & \\
\hline
\end{tabular}

Dako (Carpinteria, CA, USA); NCL: Novocastra Laboratories Ltd (Newcastle, UK); Monosan (Uden, The Neederlands); CCT: Concepta (Barcelona, Spain); IMT: Immunotech (Marseille, France). was scored in three stages, according to the following definitions: (I) No lymphocyte depletion, prominent germinal centres with well-formed follicular
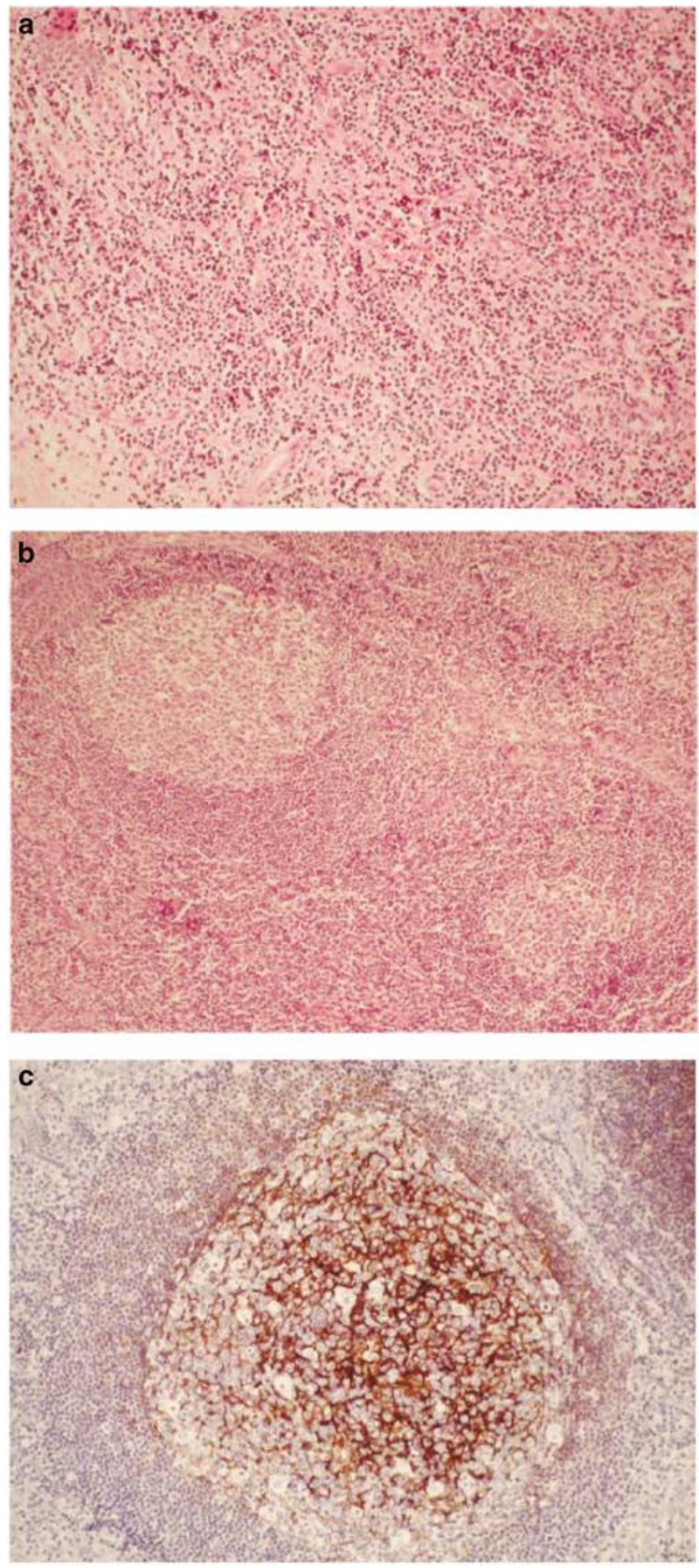

Figure 1 Changes in the architecture of the lymphoid tissue at baseline and after HAART. (a) Lymphoid tissue at baseline: lymphocyte depletion, absence of lymphoid follicles and prominent stromal vascularity (stage III). (b) The same case after 12 months of treatment: recovery of the lymphoid tissue architecture. Follicles appear well formed with large germinal centres (stage I). (c) The immunostaining for CD21 demonstrates the improved follicular dendritic cell meshwork after treatment. 
dendritic cell network (Figures 1b,c). Follicle lysis images could be seen; (II) Partial lymphocyte depletion, small germinal centres with scarce B lymphocytes and with incomplete follicular dendritic cell network (Figures 2a,b); (III) Marked
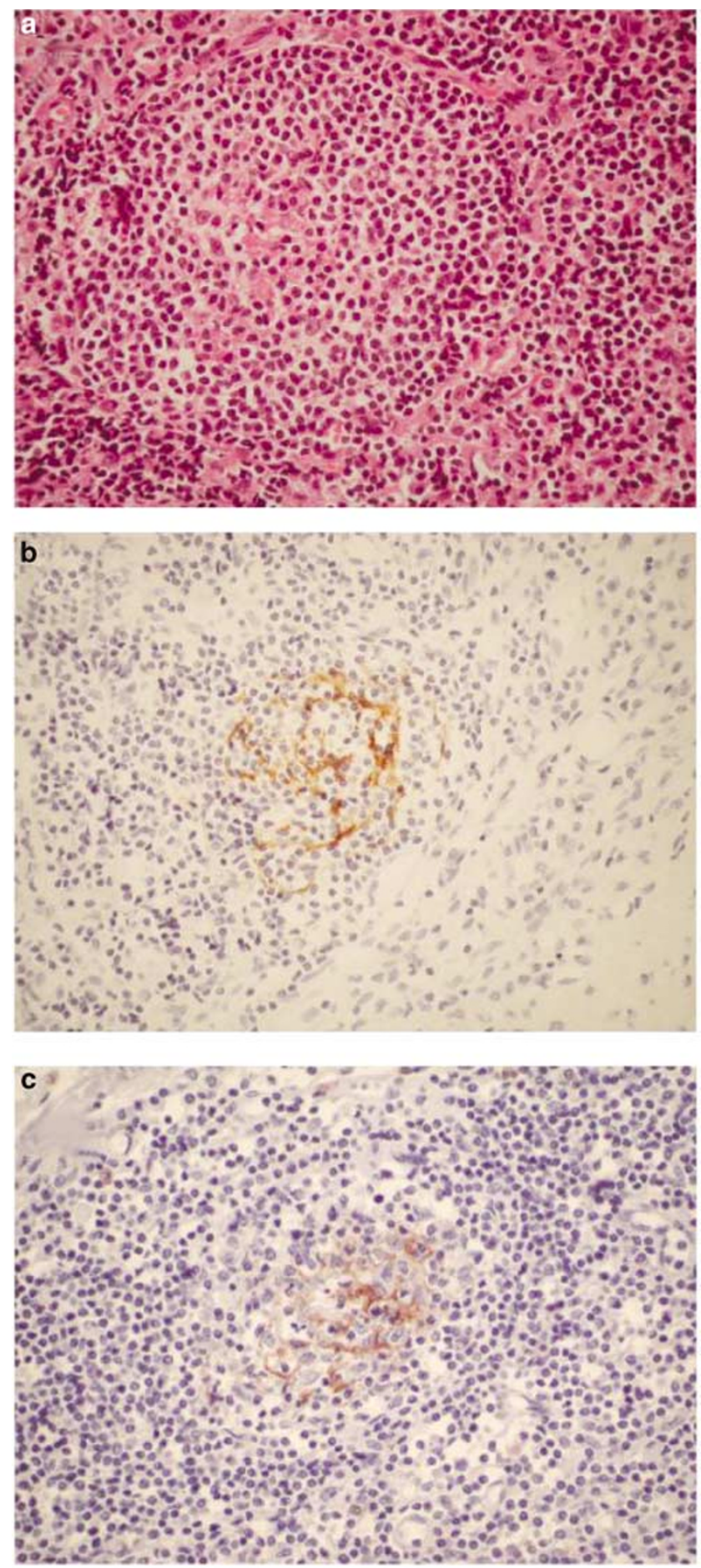

Figure 2 Lymphoid tissue before treatment, in histological stage II, (a) Partial lymphocyte depletion with small germinal centres. (b) An incomplete follicular dendritic cell meshwork is seen using the CD21 antibody. (c) The HIV-p24 immunostaining shows positivity following a follicular dendritic cell pattern. lymphocyte depletion, absence of lymphoid follicles, accumulation of plasma cells, stromal vascular proliferation (Figure 1a). Moreover, from each specimen, the total amount of lymphoid tissue and the follicular areas were evaluated by planimetry from low-power fields ( $\times 10$ objective), using a morphometer (Microimage Olympus 3.0). The mean follicular area and the proportion of follicular areas with regard to the total amount of lymphoid tissue were determined for each case.

The immunoexpression of p24 protein was quantified in four grades: 0: no positive cells; 1 : positive immunoreaction in scattered and scarce cells, with mild intensity; 2: small groups of positive cells, with mild intensity; 3 : numerous positive cells with strong intensity (Figure 2c).

\section{Quantification of Lymphocyte Cell Subsets in Lymphoid Tissue}

$\mathrm{CD} 4+$, CD8 +, cytotoxic lymphocytes (CD8 + granzyme B +), memory (CD45RO + ), naive (CD45RA + ), naive proliferating (CD45RA $+\mathrm{Ki}-67+$ ), and $\mathrm{B}$ $(\mathrm{CD} 20+)$ cells were counted in the interfollicular areas. Moreover, the intrafollicular cytotoxic lymphocytes were counted separately. In the five control cases from non-HIV-infected patients CD4+ and CD8 + cells, and cytotoxic lymphocytes were evaluated.

These cell counts were performed by means semiquantitative Image Analysis, using the morphometer Microimage of Olympus 3.0 which is connected to an Olympus BH2 microscope. In all, 10 high-power fields (HPFs), using a $\times 40$ objective, were counted. The mean value per HPF for each cell type, was calculated.

\section{Peripheral Blood Determinations}

Plasma viral load was measured using a quantitative polymerase chain reaction method (HIV Monitor test Procedure, Amplicor PCR Diagnostic; Hoffman-La Roche, Basel, Switzerland), with a limit of quantification of $20 \mathrm{copies} / \mathrm{ml}$.

CD4 and CD8 T-cell counts in peripheral blood were determined by standard flow cytometry. Subpopulations of CD3 +, CD4 + and CD8 + T cells were determined using monoclonal antibodies (all from Becton-Dickinson, Mountain View, CA, USA). The stained cells were analysed on a FacsCalibur flow cytometer. Data were analysed using CellQuest software.

\section{Statistical Study}

For the purpose of the analysis, RNA values in lymphoid tissue reported as undetectable (below 40 copies $/ \mathrm{ml}$ ) were considered equivalent to 40 copies $/ \mathrm{ml}$. Quantitative data were compared 
between groups with a Student's $t$-test for paired samples in variables with normal distribution and similar variances, or with the Wilcoxon matched pairs test for those variables without normal distribution. Spearman rank-order correlations were performed on quantitative data. A $P$-value $<0.05$ was considered significant.

\section{Results}

\section{Clinical Findings of the Patients}

The median age of the patients was 34 years (range 24-49). In all, 21 patients were male and nine were female. The risk factors for HIV-1 infection were drug addiction in nine cases, homosexual transmission in eight cases and heterosexual transmission in 13 cases. The patients had been diagnosed with HIV1 infection a median of 24 (range 13-120) months prior to initiation of HAART.

\section{Lymphoid Tissue Viral Load, Morphology of the Lymphoid Tissue and p24 Expression}

The results of the lymphoid tissue viral load, the morphological study of the lymphoid tissue and the immunoexpression of p24 are summarized in Tables 2 and 3 . In initial biopsies, before treatment, the median lymphoid tissue viral load was 1542691 copies/mg tissue, and it decreased significantly after
12 months of treatment to 8915 copies/mg tissue $(P=0.013)$. However, after 36 months of treatment, the lymphoid tissue viral load was still detectable in four out of six cases evaluated, and it did not change significantly from the previous determination (median of 12030 copies/mg tissue).

The morphological study could be performed in 26 cases at baseline. In all, 15 cases $(58 \%)$ showed an histological stage III (Figure 1a); nine cases (35\%), a stage II (Figure 2a,b); and two cases (7\%), a stage I. After 12 months of treatment, 28 biopsies could be evaluated. There was a significant improvement in the lymphoid tissue morphology $(P<0.001): 15$ cases $(54 \%)$ were in histological stage II; 13 cases $(46 \%)$, in stage I (Figure 1b,c); and none in stage III. Four out of six biopsies performed after 36 months of treatment were in histological stage I (67\%), but two were still in stage II $(33 \%)$. There was a positive statistical correlation between lymphoid tissue viral load and the histological stage: high levels of lymphoid tissue viral load correlate with high histological stages, and low levels of lymphoid tissue viral load correlate with low histological stages $(P=0.040)$.

In basal biopsies, the median follicular area was $0.05 \mathrm{~mm}^{2}$ and the median proportion of follicular areas with regard to the total amount of lymphoid tissue was $1.61 \%$ (range $0-15.52 \%$ ). These parameters increased significantly after 12 months of treatment: the median follicular area was $0.17 \mathrm{~mm}^{2}$

Table 2 Relationship between lymphoid tissue viral load (LTVL) and follicular area (FA) in HAART-treated patients

\begin{tabular}{llccc}
\hline & Time after treatment & Total cases & Median & Range \\
\hline LTVL (copies/mg tissue) & Basal & 30 & 1542691 & $405-8380952$ \\
& $12 \mathrm{mo}$ & 30 & 8915 & $<40-100000$ \\
& $36 \mathrm{mo}$ & 6 & 12030 & $<40-35000$ \\
FA $\left(\mathrm{mm}^{2}\right)$ & & & $0.013^{\mathrm{a}}$ \\
& Basal & 26 & 0.17 & $0.04-1.23$ \\
& $12 \mathrm{mo}$ & 28 & 0.15 & $0.07-0.33$ \\
\hline
\end{tabular}

${ }^{\text {a }} P$-value between samples at baseline and after 12 months of treatment.

Table 3 Relationship between histological stages and p24 expression in HAART-treated patients

\begin{tabular}{|c|c|c|c|c|c|c|c|}
\hline & Time after treatment & Total cases & & $N$. cases & & & $\mathrm{P}$-value \\
\hline \multirow[t]{4}{*}{ Histological stages } & & & I & II & III & & \\
\hline & Basal & 26 & $2(7)$ & $9(35)$ & $15(58)$ & & $<0.001^{\mathrm{a}}$ \\
\hline & $12 \mathrm{mo}$. & 28 & $13(46)$ & $15(54)$ & 0 & & \\
\hline & 36 mo. & 6 & $4(67)$ & $2(33)$ & 0 & & \\
\hline \multirow[t]{4}{*}{ p24 grades } & & & 0 & 1 & 2 & 3 & \\
\hline & Basal & 17 & 0 & $2(11)$ & 3 (18) & $12(71)$ & $<0.001^{\mathrm{a}}$ \\
\hline & $12 \mathrm{mo}$. & 20 & $10(50)$ & 7 (35) & 3 (15) & 0 & \\
\hline & $36 \mathrm{mo}$. & 6 & $2(33)$ & $4(67)$ & 0 & 0 & \\
\hline
\end{tabular}

${ }^{\mathrm{a}} P$-value between samples at baseline and after 12 months of treatment. 
$(P=0.018)$, and the median proportion of follicular areas with regard to the total amount of lymphoid tissue was $8.47 \%$ (range $2-20.59 \%) \quad(P<0.001$ ). However, these parameters did not change significantly after 36 months of treatment, when compared with those after 12 months of treatment (the median follicular area was $0.15 \mathrm{~mm}^{2}$ and the median proportion of follicular areas with regard to the total amount of lymphoid tissue was $10.72 \%$ ). There was a statistical correlation between the histological stage with both follicular area and the proportion of follicular areas with regard to the total amount of lymphoid tissue $(P<0.001)$.

The immunoexpression of p24 was assessed in 17 initial biopsies. All cases were positive with 12 cases $(71 \%)$ in grade 3 (Figure 2c); three cases $(18 \%)$, in grade 2 ; and two cases $(11 \%)$ in grade 1 . After 12 months of treatment, the immunoexpression of p24, assessed in 20 cases, decreased significantly $(P<0.001)$. However, it was still positive in 10 cases: seven in grade $1(35 \%)$, and three in grade $2(15 \%)$. p24 was negative in the other 10 cases $(50 \%)$. After 36 months of treatment, the p24 expression was still positive in four out of six cases $(67 \%)$, all them in grade 1 . In the cases with follicular structures (stages I and II) the immunoexpression of p24 was superposed on the CD21 expression (Figure 2b, c).

\section{Lymphocyte Subset in Interfollicular Areas of the Lymphoid Tissue}

The results of the counts of $\mathrm{CD} 4+, \mathrm{CD} 8+$ cells, cytotoxic lymphocytes, memory, naive, naive proliferating, and B lymphocytes in the interfollicular areas are shown in Table 4.

At baseline, the median counts of CD4 + and CD8 + cells were 251 and 246 cells per HPF, respectively. The median count of cytotoxic lymphocytes was 198 cells per HPF. A significant increase of CD $4+$ cells $(P<0.001)$ (Figures 3a,b) and decrease of CD8 + cells and cytotoxic lymphocytes (both $P<0.001$ ) was observed after 12 months of treatment (median of 456, 121, and 97 per HPF, respectively). Consequently, the ratio CD4 + /CD8 + in lymphoid tissue also increased significantly $(P<0.001)$. We found a positive correlation between the number of CD8 + and the histological stage of the lymphoid tissue $(P=0.010)$. After 36 months of treatment the mean value for each cell count did not change significantly (median CD4+: 426, CD8 + : 143 and cytotoxic lymphocytes: 89 per HPF), when compared to that of the previous determination. The tonsils of non-HIV persons, used as control cases had a higher median of CD4 + cells (638 per HPF), and a lower number of CD8 + cells (96 per HPF) and cytotoxic lymphocytes (65 per HPF), even when compared with the determinations of HIV-infected persons after treatment (Figure 3c).
Table 4 Cells per HPF in interfollicular areas of lymphoid tissue in HAART-treated patients

\begin{tabular}{|c|c|c|c|c|}
\hline & $\begin{array}{l}\text { Time after } \\
\text { treatment }\end{array}$ & Range & Median & $\mathrm{P}$-value \\
\hline CD4+ & $\begin{array}{l}\text { Basal } \\
12 \text { mo. } \\
36 \text { mo. } \\
\text { Control }\end{array}$ & $\begin{array}{r}60-449 \\
158-623 \\
345-510 \\
550-737\end{array}$ & $\begin{array}{l}251 \\
456 \\
426 \\
638\end{array}$ & $<0.001^{\mathrm{a}}$ \\
\hline CD8+ & $\begin{array}{l}\text { Basal } \\
12 \text { mo. } \\
36 \text { mo. } \\
\text { Control }\end{array}$ & $\begin{array}{l}81-343 \\
25-268 \\
60-226 \\
90-104\end{array}$ & $\begin{array}{r}246 \\
121 \\
143 \\
96\end{array}$ & $<0.001^{\mathrm{a}}$ \\
\hline $\begin{array}{l}\text { Cytotoxic } \\
\text { lymphocytes } \\
\text { (CD8+ granzyme } \\
\text { B+) }\end{array}$ & $\begin{array}{l}\text { Basal } \\
12 \text { mo. } \\
36 \text { mo. } \\
\text { Control }\end{array}$ & $\begin{array}{l}68-297 \\
41-198 \\
45-102 \\
61-75\end{array}$ & $\begin{array}{r}198 \\
97 \\
89 \\
65\end{array}$ & $<0.001^{\mathrm{a}}$ \\
\hline CD45RO+ & $\begin{array}{l}\text { Basal } \\
12 \mathrm{mo} . \\
36 \mathrm{mo} .\end{array}$ & $\begin{array}{l}240-580 \\
310-720 \\
206-482\end{array}$ & $\begin{array}{l}372 \\
496 \\
420\end{array}$ & $<0.001^{\mathrm{a}}$ \\
\hline CD45RA+ & $\begin{array}{l}\text { Basal } \\
12 \text { mo. } \\
36 \text { mo. }\end{array}$ & $\begin{array}{r}82-336 \\
164-576 \\
198-375\end{array}$ & $\begin{array}{l}192 \\
420 \\
312\end{array}$ & $<0.001^{\mathrm{a}}$ \\
\hline CD45RA+Ki67+ & $\begin{array}{l}\text { Basal } \\
12 \mathrm{mo} . \\
36 \mathrm{mo} .\end{array}$ & $\begin{array}{l}2-20 \\
4-24 \\
6-12\end{array}$ & $\begin{array}{l}10 \\
12 \\
10\end{array}$ & $0.110^{\mathrm{a}}$ \\
\hline CD20+ & $\begin{array}{l}\text { Basal } \\
12 \text { mo. } \\
36 \text { mo. }\end{array}$ & $\begin{array}{l}35-175 \\
14-132 \\
38-119\end{array}$ & $\begin{array}{r}100 \\
89 \\
81\end{array}$ & $0.160^{\mathrm{a}}$ \\
\hline
\end{tabular}

${ }^{\mathrm{a}} \mathrm{P}$-value between samples at baseline and after 12 months of treatment.

In initial biopsies, the median counts of memory, naive, and proliferating naive cells were 372, 192, and 10 per HPF, respectively. After 12 months of treatment, both memory and naive cells increased significantly (median of 496 and 420 per HPF, respectively) (both $P<0.001$ ), but the increase of naive cells was higher, and there was an improvement in the ratio naive/memory cells. Proliferating naive cells also increased, but not significantly (median of 12 per HPF). After 36 months of treatment, these parameters did not change significantly, and the median counts of memory cells were 420, naive cells 312, and the proliferating naive cells 10 per HPF. Only naive cells correlated with lymphoid tissue viral load $(P=0.045)$.

The median count of CD20 + cells (B lymphocytes) in interfollicular areas at baseline was 100 per HPF. After 12 and 36 months of treatment this parameter did not change significantly, and it was 89 and 81 per HPF, respectively.

\section{Intrafollicular Cytotoxic Lymphocytes}

Cytotoxic lymphocytes (CD8 + granzyme B + cells) inside the follicular structures were counted in 11 

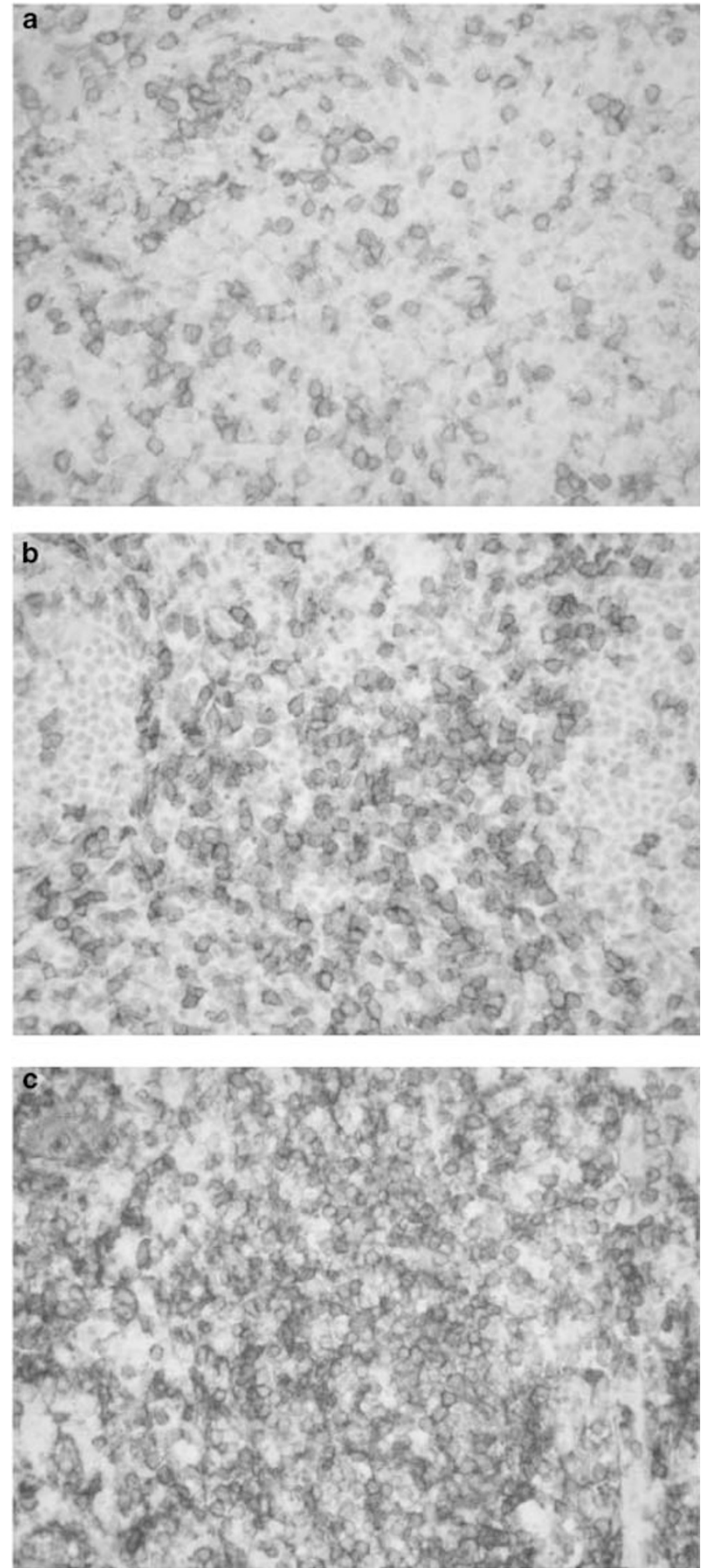

Figure 3 CD4 + cells in interfollicular areas of the lymphoid tissue. (a) Before treatment, the number of $\mathrm{CD} 4+$ cells is impaired. (b) The same case after 12 months of HAART shows recovery of the number of CD4 + cells. (c) Lymphoid tissue of non HIV-infected person (control case): higher number of CD4 + than that of HIV-infected persons, even after treatment.

cases with follicular structures in the initial biopsies. In these cases, the median count of intrafollicular cytotoxic lymphocytes was 20 cells per HPF (range 7-30). After 12 months of treatment, the median count of cytotoxic lymphocytes decreased significantly, and it was of 11 cells per HPF (range $5-19)(P=0.004)$. After 36 months of treatment, the median intrafollicular cytotoxic lymphocyte count was 16 (range 6-22), and there was no statistical difference when compared to the previous determination. The median intrafollicular cytotoxic lymphocytes counted in the tonsillar lymphoid tissue of non-HIV-infected persons (control cases) was two cells per HPF (range 1-3).

\section{Peripheral Blood Determinations}

Plasma viral load decreased significantly after 12 months of treatment $(P<0.001)$, and turned into undetectable in all cases. It was still undetectable after 36 months of treatment. We found a statistical correlation between plasma viral load and the histological stage of the lymphoid tissue $(P=0.013)$; but not with lymphoid tissue viral load or other lymphoid tissue parameters.

In peripheral blood also there was a significant increase of CD4 $+(P=0.02)$ and decrease of CD8 + after treatment $(P=0.019)$. Thus, the ratio $\mathrm{CD} 4+/$ CD8 + cells in peripheral blood increased significantly after treatment $(P<0.001)$. At the moment of the third biopsy, after 36 months of treatment, these parameters did not change significantly.

The ratio CD4 + /CD8 + was lower in peripheral blood than in lymphoid tissue. We did not find statistical correlation between CD4 + and CD8 + in peripheral blood with CD4 + and CD8 + in lymphoid tissue. However, the ratio CD4 +/CD8 + in peripheral blood correlated with the same ratio in lymphoid tissue $(P=0.049)$.

\section{Discussion}

Tonsillar biopsies can be performed repeatedly in the same patient and provide an accessible source of lymphoid tissue. In spite of these biopsies being small samples, they are useful to measure the HIV RNA (lymphoid tissue viral load), to study the lymphoid tissue architecture, and to perform immunohistochemical procedures for p24 antigen and lymphoid cell subset assessment. The quantification of lymphocyte cell subsets can be more exact using flow cytometry. However, this technique requires larger amounts of lymphoid tissue and does not supply other useful information, such as the lymphoid tissue architecture and lymphoid cells arrangement.

In HIV infection, the follicular dendritic cells are responsible for the transmission of the infection, binding virions on their surfaces in immune complexes. ${ }^{1-4}$ We have demonstrated viral presence in lymphoid tissue by means of polymerase chain reaction and immunohistochemistry using a monoclonal antibody which recognizes the HIV p24 core antigen. ${ }^{22}$ Some reports have stated that the 
localization of the immunohistochemical reaction of HIV p24 gives results parallel to viral RNA determined by hybridization in situ. ${ }^{23,24}$ In our cases, the immunohistochemical reaction for HIV p24 was positive mainly following a follicular dendritic cell distribution, as the immunoexpression of this antigen has been superposed on that of CD21, a follicular dendritic cell marker (Figure 2b, c). Retention of infectivity of HIV-1 associated with follicular dendritic cells indicates that this compartment behaves as a continuing source of infection.

After treatment with HAART, the lymphoid tissue viral load and the immunoexpression of p24 antigen decreased significantly. However, lymphoid tissue viral load did not disappear in all cases. Moreover, p24 antigen was still positive in half of the cases after 12 months of treatment, and even in four cases out of six after 36 months of treatment, in spite of all cases showing an undetectable plasma viral load. These facts demonstrate that the study of lymphoid tissue is more accurate than that of the peripheral blood for determining the viral suppression with the treatment.

The architectural changes in lymphoid tissue during HIV-1 infection have been exhaustively described in past years and have been related to the stage of the disease. ${ }^{12,13}$ The HIV-1 infection produces firstly a lymphoid follicular hyperplasia, in which germinal centres are prominent. In this stage, the mantle cell can be effaced, and follicle lysis images can be seen. The following stage in the progression of the infection is the follicular involution of the lymphoid tissue. In this stage, follicles are small and the meshwork of follicular dendritic cell is disrupted, the follicles are mainly formed by these cells, whereas B centre cells are scarce. When the disease progresses, there is a depletion of lymphocytes and the follicles disappear. In this stage, there is usually stromal vascular proliferation. These histological alterations described above correlate perfectly with the clinical evolution of the HIV-1 infection in untreated HIV-1 infected persons. ${ }^{12,13}$ In this study, we have demonstrated that these morphological alterations correlate significantly with the quantification of HIV-1 RNA in lymphoid tissue and peripheral blood. In initial biopsies, the lymphoid tissue in histological stage II had lower lymphoid tissue viral load than those in stage III. After treatment, the cases in stage I had lower lymphoid tissue viral load than those in stage II. In fact, high levels of lymphoid tissue viral load correlated with advanced histological stages, even when T-cell subsets in peripheral blood did not show such an extreme alteration. Before initiating treatment, all patients had a number of CD4+ lymphocytes in peripheral blood $>500 \times 10^{6} / 1$, and at the same time, in 15 out of $26(58 \%)$ cases, the lymphoid tissue showed destruction of the lymphoid follicles and prominent stromal vascularity, and it was classified as stage III (Figure 1a). Our study also confirms the recovery of lymphoid tissue architecture after treatment with HAART, as most cases evolved to stages I or II, in which the follicular structures reappeared well or partially formed, respectively (Figures 1b,c). The capacity of recovery of the follicular dendritic cells after treatment with HAART had been pointed out in previous studies. ${ }^{20,21,25}$

The architectural changes in lymphoid tissue are associated with a progressive alteration in the balance of T-cell subsets. The infection produces a decrease of CD4 $+\mathrm{T}$ lymphocytes, which we have demonstrated clearly in lymphoid tissue before treatment. CD8 $+\mathrm{T}$ lymphocytes, specially the cytotoxic lymphocytes, which express immunohistochemically granzyme B, TIA-1 and esterase, are increased in first phases of the infection. ${ }^{13}$ These cells are found mainly in the interfollicular areas, and also inside the follicular structures, attracted by a chemotactic effect produced by the virus. ${ }^{11} \mathrm{We}$ have observed a high number of CD8 + cells, most of them cytotoxic lymphocytes, in interfollicular areas, as well as inside the follicular structures, before treatment. After treatment, we have observed a significant increase of CD4 + and decrease of CD8 + cells and cytotoxic lymphocytes, the latter in both interfollicular and intrafollicular areas. However, in spite of treatment, we have demonstrated that this improvement in the T-cell subsets do not reach the normal parameters observed in tonsils of non-HIV-infected persons, used as control cases. These observations also confirm that the presence of high number of intrafollicular cytotoxic lymphocytes could be considered a hallmark of HIV infection. This is the first time that lymphoid tissue of HIV-infected persons has been studied after 36 months of treatment with HAART. Our results indicate that the morphology and the lymphoid subsets do not improve after such a long period of treatment.

In spite of the fact that the values in peripheral blood reflect the events in lymphoid tissue, T cells in the circulating blood represent only $1-2 \%$ of the total body pool. We have not found a correlation between CD4 + and CD8 + cells in both compartments before and after treatment. The ratio CD $4+$ I CD8 + was higher in lymphoid tissue than in peripheral blood, as other studies using flow cytometry have observed. ${ }^{26}$ However, we have found a positive statistical correlation between the ratio CD4 + /CD8 + in lymphoid tissue and peripheral blood, which indicates a constant equilibrium between both compartments.

CD4 + and CD8 + lymphocytes emigrate from the thymus when they are physiologically matured, and they express a specific isotype of the CD45 family, the CD45RA antigen. ${ }^{27}$ These cells, immunologically naive, turn into a CD45RO + phenotype characteristic of memory $\mathrm{T}$ cells, after challenging an antigen in the periphery. ${ }^{28}$ The balance between the naive and memory $\mathrm{T}$ cells is crucial for maintaining an efficient immune response. In HIV infection, naive 
and memory CD4+ T-cell counts decrease in different stages of disease. Persons with HIV infection initially show a selective loss of memory cells, and as absolute CD4 + T-cell counts decrease, the naive CD4 T cells are also lost. ${ }^{29}$ These events can be explained taken into account the several mechanisms by which HIV depletes CD4 + T lymphocytes. On one hand, HIV induces an increased immune activation that leads a persistent proliferation and a higher rate of death of CD4 + T cells. ${ }^{4-7}$ On the other, in HIV-infected persons there is an impaired production of $\mathrm{T}$ cells by suppression of hematopoiesis. ${ }^{9,10}$ These mechanisms do not act equally on CD8 + T cells, which increase until the late stages of HIV-1 infection, due to an increased activation, but not an increase in the death rate. ${ }^{6,8}$

The treatment with HAART produces a recovery of the immune response, which is dependent on the regeneration of the naive and memory CD $4+\mathrm{T}$ cells. In first weeks after initiating the treatment there is a release of memory cells from lymphoid tissue to peripheral blood, ${ }^{30}$ but later there is an increase of memory cells in both compartments due to a decrease of $\mathrm{CD} 4+$ cells proliferation and death. ${ }^{6,7,14,31}$ However, the treatment with HAART also produces an increase of newly generated naive cells due to an increase of thymic production ${ }^{14-16}$ and/or a peripheral expansion of naive cells. ${ }^{32}$ In our study, we have observed an increase of both naive and memory cells in interfollicular areas of the lymphoid tissue, after 12 and 36 months of HAART. Interestingly, the relation naive/memory cells improved after treatment, indicating that the treatment effect on the T-cell turnover works preferably on the lymphoid production, at this time. The proliferating naive cells (CD45RA + Ki-67 +) have shown only a slight increase after 12 months of treatment. It has been proposed the value of naive cells as a marker of the improvement of the immunity of these patients during treatment. ${ }^{26}$ We have found a correlation between the increase of naive cells in lymphoid tissue and the decrease of lymphoid tissue viral load. In our cases, after treatment, there was an increase of naive, memory and CD $4+$ cells in interfollicular areas of the lymphoid tissue, whereas a decrease of CD8 + cells and a practically invariable number of B lymphocytes occurred in this site. Therefore, most of these increased naive and memory cells must be CD4 + cells.

In conclusion, the changes in the lymphoid tissue architecture correlate with the viral quantification in both lymphoid tissue and peripheral blood. In spite that the treatment with HAART produces a significant improvement of all the parameters studied in lymphoid tissue, this recovery is not complete, even after 36 months of treatment. Thus, the study of lymphoid tissue in HIV infection provides a more accurate information about viral reservoir and cellular immunological improvement than peripheral blood determinations, for monitoring responses to therapy.

\section{Acknowledgements}

We thank Margarita Mainar and Elena Gonzalvo for performing the immunohistochemical techniques. Dr José M Miró was a recipient of a Research Grant from IDIBAPS, Barcelona, Spain. This study has been partially supported by 'Red Temática Cooperativa de Investigación en Sida del FIS (Red de Grupos 173)'.

\section{References}

1 Spiegel H, Herbst H, Niedobitek G, et al. Follicular dendritic cells are major reservoir for human immunodeficiency virus type 1 in lymphoid tissues facilitating infection of CD $4+\mathrm{T}$ helper cells. Am J Pathol 1992;140:15-22.

2 Haase AT, Henry K, Zupancic M, et al. Quantitative image analysis of HIV-1 infection in lymphoid tissue. Science 1996;274:985-989.

3 Cavert W, Notermans DW, Staskus K, et al. Kinetics of response in lymphoid tissue to antiretroviral therapy of HIV-1 infection. Science 1997;276:960-964.

4 Tenner-Racz K, Stellbrink HJ, vanLunzen J, et al. The unlarged lymph nodes of HIV-1-infected, asymptomatic patients with high CD4 T cell counts are sites for virus replication and CD4 $\mathrm{T}$ cell proliferation. The impact of Highly Antiretroviral Therapy. J Exp Med 1998;187:949-959.

5 Hellerstein M, Hanley MB, Cesar D, et al. Directly measured kinetics of circulating $\mathrm{T}$ lymphocytes in normal and HIV-1-infected humans. Nat Med 1999; 5:83-89.

6 Mohri H, Perelson AS, Tung K, et al. Increased turnover of T lymphocytes in HIV-1 infection and its reduction by antiretroviral therapy. J Exp Med 2001; 194:1277-1287.

7 Kovacs JA, Lempicki RA, Sidorov IA, et al. Identification of dynamically distinct subpopulations of $\mathrm{T}$ lymphocytes that are differentially affected by HIV. J Exp Med 2001;194:1731-1741.

8 Ribeiro RM, Morí H, Ho DD, et al. In vivo dynamics of $\mathrm{T}$ cell activation, proliferation, and death in HIV-1 infection: why are CD4+ but not CD8+ T cells depleted? Proc Natl Acad Sci 2002;99:15572-15577.

9 Moses A, Nelson J, Bagby GC. The influence of immunodeficiency virus-1 on hematopoiesis. Blood 1998;91:1479-1495.

10 Huang SS, Barbour JD, Deeks SG, et al. Reversal of human immunodeficiency virus type 1-associated hematosuppression by effective antiretroviral therapy. Clin Infect Dis 2000;30:504-510.

11 Laman JD, Claassen E, Van Rooijen N, et al. Immune complexes on follicular dendritic cells as a tarjet for cytolytic cells in AIDS. AIDS 1989;3:543-548.

12 Chadburn A, Metroka C, Moudradian J. Progressive lymph node histology and its prognostic value in patients with acquired immunodeficiency syndrome and AIDS-related complex. Hum Pathol 1989;20: 579-587.

13 Knowles DM, Chadburn A. Lymphadenopathy and lymphoid neoplasms associated with the acquired immunodeficiency syndrome (AIDS). In: Knowles DM (ed). Neoplastic Hematopathology. William and Wilkins: Baltimore, 2001, pp 987-989. 
14 McCune JM, Hanley MB, Cesar D, et al. Factors influencing T-cell turnover in HIV-1-seropositive patients. J Clin Invest 2000;105:R1-R8.

15 Franco JM, Rubio A, Martinez-Moya M, et al. T-cell repopulation and thymic volume in HIV-1-infected adult patients after highly active antiretroviral therapy. Blood 2002;99:3702-3706.

16 Kolte L, Dreves AM, Ersboll AK, et al. Association between larger thymic size and higher thymic output in human immunodeficiency virus-infected patients receiving highly active antiretroviral therapy. J Infect Dis 2002;185:1578-1585.

17 Martinez E, Arnedo M, Giner V, et al. Lymphoid tissue viral burden and duration of viral supresión in plasma. AIDS 2001;15:1-6.

18 Naverrete P, Morente V, Garcia F, et al. Predictors of tonsillar tissue HIV-1 viral burden at baseline and after 1 year of antiretroviral therapy. Antiviral Therapy 2003;8:635-637.

19 Lange CG, Valdez H, Connik E, et al. Limited immune restoration after 3 years suppression of HIV-1 replication in patients with moderately advanced disease. AIDS 2002;16:1859-1866.

20 Macias J, Japon MA, Leal M, et al. Structural normalization of the lymphoid tissue in asymptomatic HIVinfected patients after 48 weeks of potent antiretroviral therapy. AIDS 2001;15:2371-2378.

21 Schacker TW, Nguyen PL, Martinez E, et al. Persistent abnormalities in lymphoid tissues of HIV-infected persons successfully treated with anti-retroviral therapy. J Infect Dis 2002;108:1092-1097.

22 Kaluza G, Willems WR, Lohmeyer J, et al. A monoclonal antibody that recognizes a formalin-resistant epitope on the p24 core protein of HIV-1. Path Res Pract 1992;188:91-96.

23 Wenig BM, Thompson LDR, Frankel SS, et al. Lymphoid changes of the nasopharyngeal and palatine tonsils that are indicative of human immunodeficiency virus infection. A clinicopathologic study of 12 cases. Am J Surg Pathol 1996;20:572-587.

24 Kuster H, Opravil M, Ott P, et al. Treatment-induced decline of human immunodeficiency virus-1 p24 and HIV-1 RNA in lymphoid tissue of patients with early human immunodeficiency virus-1 infection. Am J Pathol 2000;156:1973-1986.

25 Zhang ZQ, Schuler T, Cavert W, et al. Reversibility of the pathological changes in the follicular dendritic cell network with treatment of HIV-1 infection. Proc Natl Acad Sci 1999;96:5169-5172.

26 Nokta MA, Li XD, Nichols J, et al. Homeostasis of naive and memory $\mathrm{T}$ cell subpopulations in peripheral blood and lymphoid tissues in the context of human immunodeficiency virus infection. J Infect Dis 2001; 183:1336-1342.

27 Spits H, Lanier LL, Phillips JH. Development of human T and natural killer cells. Blood 1995;85:2654-2670.

28 Clement LT. Isoforms of the CD45 common leukocyte antigen family: markers of human $\mathrm{T}$ cell differentiation. J Clin Immunol 1992;12:1-10.

29 Ginaldi L, DeMartinis M, D’Ostilio A, et al. Activated naive and memory CD4+ and CD8+ subsets in different stages on HIV infection. Pathobiology 1997; 65:91-99.

30 Bucy RP, Hockett RD, Derdeyn CA, et al. Initial increase in blood CD4+ lymphocytes after HIV antiretroviral therapy reflects redistribution from lymphoid tissues. J Clin Invest 1999;103:1391-1398.

31 Zhang ZQ, Notermans DW, Sedgewick G, et al. Kinetics of CD4+ $\mathrm{T}$ cell repopulation of lymphoid tissues after treatment of HIV-1 infection. Proc Natl Acad Sci 1998;95:1154-1159.

32 Haynes BF, Hale LP, Weinhold KJ, et al. Analysis of the adult thymus in reconstitution of $\mathrm{T}$ lymphocytes in HIV-infection. J Clin Invest 1999;103:453-460. 